CONGENITAL HEART DISEASE

\title{
Total percutaneous correction of a tetralogy of Fallot variant with dominant pulmonary valve stenosis
}

\author{
E B Sideris, B Macuil, S Justiniano, P S Rao
}

Heart 2005;91:345-347. doi: 10.1136/hrt.2003.031682

\begin{abstract}
Objective: To study the feasibility, efficacy, and safety of total percutaneous correction of a tetralogy of Fallot variant with dominant pulmonary valve stenosis.

Design: Percutaneous correction of a variant of tetralogy of Fallot with dominant pulmonary valve stenosis, on the basis that there are transcatheter methods for the correction of malalignment-type ventricular septal defect (VSD) (transcatheter patch) and valvar pulmonary stenosis (balloon valvoplasty).

Patients: Two patients with tetralogy of Fallot, 4 and 7 years old, were admitted for percutaneous correction. Their aortic saturations were $72 \%$ and $88 \%$. Both had severe right ventricular oufflow obstruction with dominant valvar pulmonary stenosis with total gradients of 120 and $70 \mathrm{~mm} \mathrm{Hg}$. Large malalignment subaortic VSDs, 14 and $16 \mathrm{~mm}$ in diameter, were present. The first patient had a previous percutaneous correction of a small atrial septal defect and an aortopulmonary collateral. Interventions: Balloon valvoplasty was first performed, followed by balloon test occlusion of the VSD and double balloon patch occlusion. Forty eight hours after implantation the supporting balloons were extracted, releasing the patches.

Results: Both patients became acyanotic with oxygen saturations of $96 \%$. There was mild residual infundibular stenosis with 40 and $30 \mathrm{~mm} \mathrm{Hg}$ gradients. Both VSDs were effectively occluded with only trivial residual shunts. One patient developed mild haemolysis, which resolved spontaneously in a few days. Both patients were doing well at six and 12 months' follow up visits.

Conclusions: Total percutaneous correction of the tetralogy of Fallot variants with dominant pulmonary valve stenosis is feasible and successful. Larger clinical trials are required to further assess effectiveness and safety.
\end{abstract}

See end of article for

authors' affiliations

Dr Eleftherios B Sideris,

Athenian Institute of

Pediatric Cardiology, 21

Rizariou Street, Athens

15233, Greece;

terry@hol.gr

Accepted 27 April 2004

.....................

$\mathrm{T}$ etralogy of Fallot is the most common cyanotic heart disease in children. It consists of right ventricular outflow obstruction, malalignment-type subaortic ventricular septal defect (VSD), overriding aorta, and right ventricular hypertrophy. ${ }^{1}$ Total correction is performed by open heart surgery, where both the stenotic right ventricular outflow and the VSD are repaired. Palliation may be required for some patients before the total correction. The landmark for the beginning of both paediatric heart surgery and paediatric cardiology was the performance of a BlalockTaussig shunt in a cyanotic patient with tetralogy of Fallot about 50 years ago. ${ }^{2}$ The evolution of treatment of tetralogy of Fallot from palliative to corrective surgery in infants and children was aided by an increasing role of transcatheter interventions. We present two cases of total percutaneous correction of a tetralogy of Fallot variant with dominant pulmonary stenosis, which in our opinion epitomises the progress made in the management of this disease.

\section{PATIENTS AND METHODS}

Two patients with known tetralogy of Fallot ( 7 and 4 years old) were admitted for possible percutaneous total correction. There were both cyanotic with their symptoms becoming worse over the years. Physical examination and ECG were consistent with tetralogy of Fallot. Chest radiography showed boot shaped hearts and right aortic arch.

Echocardiography revealed significant aortic overriding with non-restrictive subaortic VSDs (fig lA). Both patients had dominant pulmonary valve stenosis and mild infundibular pulmonary stenosis. Pulmonary arteries were small, without significant branch stenosis. The first patient had undergone two additional transcatheter interventions seven months previously: a small atrial septal defect repaired by an

Amplatzer device, and an aortopulmonary collateral occluded by a Gianturco coil.

Cardiac catheterisation and angiography confirmed the diagnosis of tetralogy of Fallot (fig 2A) with dominant severe pulmonary valvar stenosis and associated mild infundibular stenosis in both cases (table 1). There were large subaortic non-restrictive VSDs with equalisation of left ventricular and right ventricular peak systolic pressures. Aortic saturations were $72 \%$ and $88 \%$. Informed consent was obtained from the parents after ethical committee approval, before the total percutaneous corrections were attempted. Pulmonary valvoplasty was performed first with angioplasty balloons (NuMED, Nicholville, New York, USA) $2 \mathrm{~mm}$ larger than the pulmonary annulus.

The VSD was easily crossed antegradely (from the right ventricle) and an arteriovenous wire connection was established. Test balloon occlusion was performed under fluoroscopy, echocardiography, and pressure monitoring with large sizing balloons (Sideris sizing balloon; NuMED). The occluding diameters of the defects were $14 \mathrm{~mm}$ and $16 \mathrm{~mm}$ and there was no change in the systemic pressure after 10 minute balloon occlusion of the defects. A 12 French long sheath (Cook, Bloomington, Indiana, USA) was introduced transvenously over the wire and its tip was positioned in the ascending aorta. A double balloon patch (Custom Medical Devices, Athens, Greece) was introduced over the wire and was released in the ascending aorta. The distal balloon/patch was inflated with a dilute contrast solution at a diameter $1 \mathrm{~mm}$ larger than the diameter found by balloon sizing and it was pulled back until the defect was occluded. The proximal balloon was inflated in the right ventricle with the same volume as the distal balloon (fig 1B). The arteriovenous wire was extracted. The whole procedure was performed under 

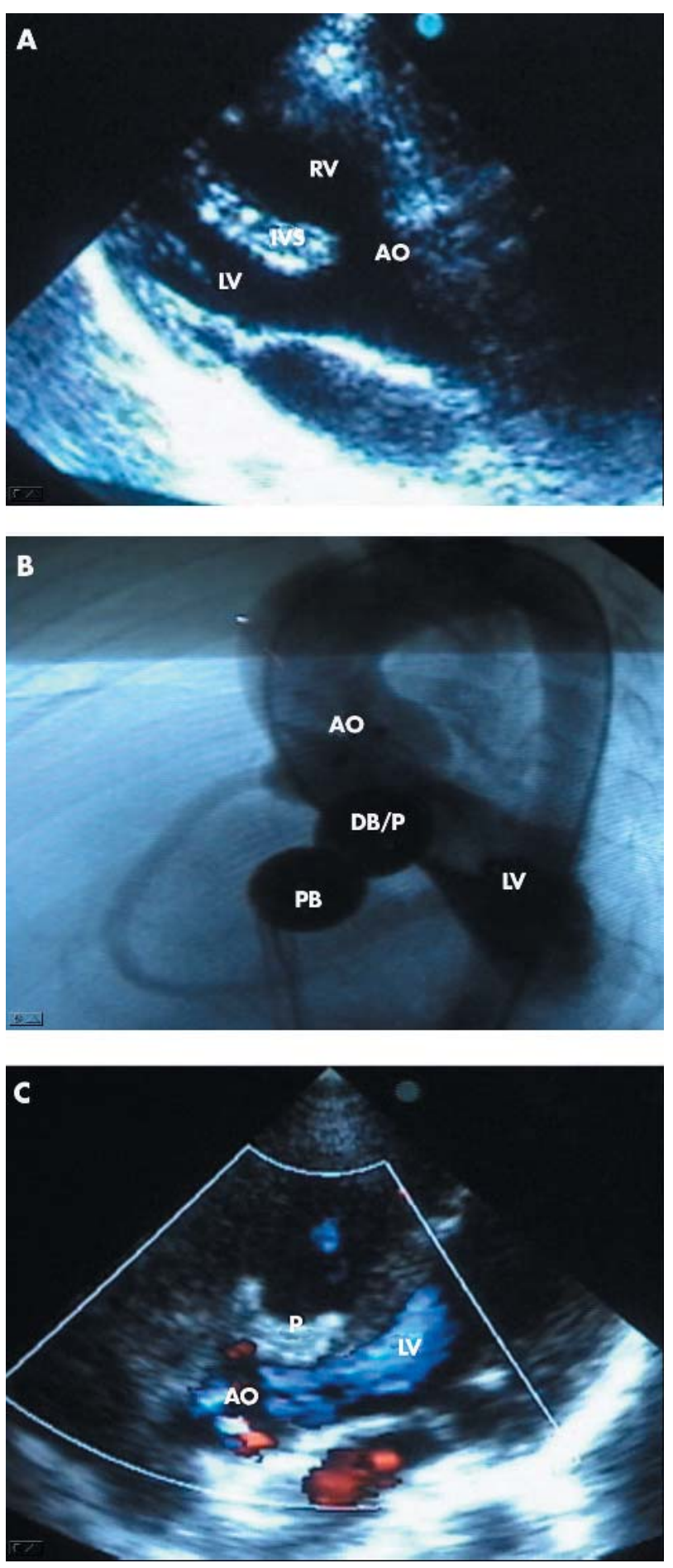

Figure 1 Case 1. (A) Two dimensional echocardiogram on long axis view showing a large subaortic ventricular septal defect (VSD) and significant aortic overriding. AO, aorta; IVS, interventricular septum; LV, left ventricle; RV, right ventricle. (B) Long axial angiographic view showing transcatheter patch occlusion of the malalignment VSD. The distal balloon/patch (DBP) is inflated on the left side of the ventricular septum with the proximal balloon (PB) on the right side. The defect is fully occluded. (C) Five chamber apical echocardiographic view showing complete occlusion of the VSD after patch (P) release (48 hours).

fluoroscopy, echocardiography, and pressure monitoring. The double balloon catheter was immobilised in the groin and the patients were taken to the intensive care unit for overnight observation. Post-implantation chest radiographs
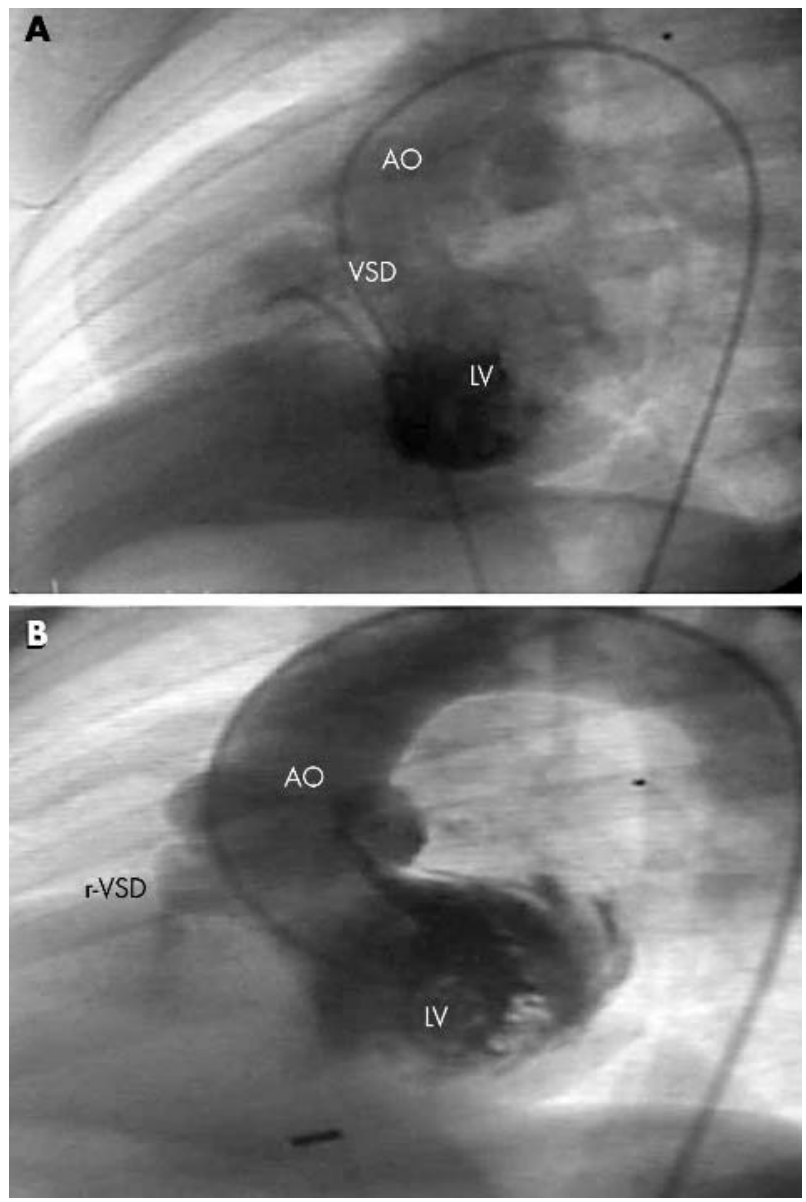

Figure 2 Case 2. (A) Left anterior oblique projection of a left ventricular angiogram showing a large aorta, significant overriding, and large subaortic VSD. (B) Left ventricular angiogram on left anterior oblique projection after patch release (48 hours) showing effective occlusion of the VSD with a trivial residual shunt. $r-V S D$, residual ventricular septal defect.

and transthoracic echocardiograms were obtained. The patches were released under fluoroscopy and echocardiography in 48 hours. ${ }^{3}$ Both patients were followed up noninvasively after six and 12 months.

\section{RESULTS}

Pulmonary valvoplasty resulted in relief of the valvar obstruction with mild residual infundibular gradient (40 and $30 \mathrm{~mm} \mathrm{Hg}$ ). Full occlusion of the VSDs was noticed by echocardiography and left ventricular cineangiography (fig 1B), right after double balloon occlusion. The absence of significant left ventricular outflow gradient was confirmed during pullback of the angiographic catheter from the left ventricle to the aorta. Upon patch release both patients had effective occlusions (fig lC) with a trivial residual shunt in one (fig 2B). The average procedure and fluoroscopy times were 90 and 30 minutes, respectively, with additional 15 and three minutes for patch release. Heparin ( $100 \mathrm{U} / \mathrm{kg}$ ) was used during the procedure and aspirin for a month. Antibiotics (cephalosporins) were given for 72 hours. Both patients underwent the procedures uneventfully and they were acyanotic when discharged (oxygen saturation 96\%). A brief episode of mild haemolysis in the first patient was resolved in a few days. The patients remained asymptomatic and acyanotic on follow up at six and 12 months after the procedure. The infundibular gradient has remained unchanged by Doppler. 
Table 1 Haemodynamic function before and after interventions and at follow up

\begin{tabular}{|c|c|c|c|c|c|c|}
\hline & \multicolumn{2}{|l|}{ Before } & \multicolumn{2}{|l|}{ After } & \multicolumn{2}{|c|}{ Follow up } \\
\hline & Case 1 & Case 2 & Case 1 & Case 2 & Case 1 & Case 2 \\
\hline $\begin{array}{l}\text { Aortic saturation (\%) } \\
\text { RVO gradient }(\mathrm{mm} \mathrm{Hg}) \\
\text { VSD size }(\mathrm{mm}) \\
\text { Balloon/patch size (mm) } \\
\text { LV/RV pressure }(\mathrm{mm} \mathrm{Hg})\end{array}$ & $\begin{array}{l}72 \\
120 \\
14 \\
15 \\
120 / 120\end{array}$ & $\begin{array}{l}88 \\
70 \\
16 \\
17 \\
100 / 100\end{array}$ & $\begin{array}{l}96 \\
44 \\
0 \\
\text { NA } \\
90 / 40\end{array}$ & $\begin{array}{l}96 \\
30 \\
1 \\
\text { NA } \\
90 / 40\end{array}$ & $\begin{array}{l}96 \\
40 \\
0 \\
\text { NA } \\
\text { NA }\end{array}$ & $\begin{array}{l}96 \\
30 \\
1 \\
\text { NA } \\
\text { NA }\end{array}$ \\
\hline
\end{tabular}

LV, left ventricle; NA, not applicable; RV, right ventricle; RVO, right ventricular oufflow; VSD, ventricular septal defect.

\section{DISCUSSION}

This is a rare variant of tetralogy of Fallot, where the dominant right ventricular outflow obstructive lesion was severe pulmonary valve stenosis, which was amenable to balloon valvoplasty. The result of the pulmonary balloon valvoplasty was successful and the patients had mild residual infundibular stenosis. The subaortic VSD is considered a challenging lesion for interventional repair because of the deficient subaortic rim and the malalignment. This VSD was successfully occluded by transcatheter patch in both patients.

The transcatheter patch is a polyurethane device delivered by balloon with a three dimensional structure, requiring a minimal rim to sit correctly. Furthermore, the absence of any wires diminishes the chances of aortic valve damage. The patch requires up to 48 hour balloon support until it is embedded in the septal wall. Fibrin is initially responsible for patch attachment with endothelialisation following very quickly. ${ }^{4}$ Accelerated patch release in less than 24 hours is also possible. ${ }^{5}$ The balloon /patch diameter is selected to be $1 \mathrm{~mm}$ larger than the balloon occluding diameter of the defect. The patch can be retrieved at any time before the release, since it is connected to a thread that is pulled after balloon withdrawal. ${ }^{3}$

The transcatheter patch has been applied successfully in the occlusion of various heart defects. ${ }^{35-8}$

The total correction of the tetralogy of Fallot variant epitomises the progress interventional cardiology has made the past few years, including the procedures performed in our patients, such as coil occlusion of collaterals, ${ }^{8}$ atrial septal defect repair, ${ }^{910}$ and pulmonary valvoplasty. ${ }^{11}$ The transcatheter patch VSD occlusion ${ }^{3}$ is probably preferable to disk device occlusion, ${ }^{12}$ since it can be applied in malalignment VSDs (three dimensional structure), has minimal rim requirements, and is unlikely to cause aortic valve damage, since it is wireless.

The diagnostic labelling of this case may be a subject of debate for the pathologist. Our opinion is that we had a cyanotic tetralogy of Fallot variant with dominant severe pulmonary valve stenosis and mild infundibular pulmonary stenosis. The following findings support this view: significant aortic overriding; large non-restrictive malalignment VSDs; small or normal pulmonary arteries without post-stenotic dilatation; presence of aortopulmonary collaterals; and right aortic arch. The additional ASD makes the first case a pentalogy of Fallot.

The physiology of both patients was that of cyanotic tetralogy of Fallot with predominant shunt at the VSD level.

In conclusion, total transcatheter correction of the tetralogy of Fallot variant with dominant pulmonary valvar stenosis in feasible and appeared effective and safe in the two described cases. Larger clinical trials are justified.

\section{Authors' affiliations}

E B Sideris, P S Rao, Division of Pediatric Cardiology, University of Texas Medical School, Houston, Texas, USA

B Macuil, S Justiniano, Premier Octubre Hospital, Mexico City, Mexico

E B Sideris is the inventor of the transcatheter patch.

\section{REFERENCES}

1 Fallot A. Contribution a l'anatomie pathologique de la maladie bleu (cyanose cardiaque). Marseille Med 1888;25:77-138.

2 Taussig HB. Congenital malformations of the heart, 2nd ed, vol 2. Cambridge: Harvard University Press, 1960:3-10.

3 Sideris EB, Toumanides S, Macuil B, et al. Transcatheter patch correction of secundum atrial septal defects. Am J Cardiol 2002;89:1082-6.

4 Sideris EB, Sideris EC, Stamatelopoulos SF, et al. Transcatheter patch occlusion of experimental atrial septal defects. Cathet Cardiovasc Intervent 2002; 57:404-7.

5 Sideris EB, Macuil B, Pursanov M, et al. Transcatheter patch occlusion of perimembranous ventricular septal defects. J Am Coll Cardiol 2003;(suppl 473A): 1021-57.

6 Sideris EB, Macuil B, Zhang J, et al. Transcatheter perimembranous ventricular septal defect occlusion by wireless devices. Eur Heart J 2001;22(suppl):2536 [abstract].

7 Sideris EB, Haddad J, Rao PS, The role of the "Sideris" devices in the occlusion of ventricular septal defects. Curr Interv Cardiol Rep $2001 ; 3: 349-53$.

8 Sideris EB, Rao PS, Macuil, et al. The adult with the giant patent ductus arteriosus: the transcatheter occlusion challenge. Circulation $2001 ; 104$ (suppl):593 [abstract].

9 Kreutzer J, Perry SB, Jonas RA, et al. Tetralogy of Fallot with diminutive pulmonary arteries: preoperative pulmonary valve dilatation and transcatheter rehabilitation of pulmonary arteries. J Am Coll Cardiol 1996;27:1741-7.

10 King TD, Mills NL. Nonoperative closure of atrial septal defects. Surgery 1974;75:383-8.

11 Sluysmans T, Neven B, Ruboy J, et al. Early balloon dilatation of the pulmonary valve in infants with tetralogy of Fallot: risks and benefits. Circulation 1995;91:1506-11.

12 Bass JL, Kaira GS, Arora R, et al. Initial human experience with the Amplatzer perimembranous ventricular septal defect occluder device. Cathet Cardiovasc Intervent 2003;58:238-45. 